\title{
Bacteriological Examination of Clinically Affected Milk Samples from Doe Suspected of Mastitis
}

\author{
Subha Ganguly ${ }^{1}$, Praveen Kumar Praveen ${ }^{2}$, Rajesh Wakchaure ${ }^{3}$ \\ Parveez Ahmad Para ${ }^{4}$
}

${ }^{1}$ Associate Professor, Department of Veterinary Microbiology, ${ }^{2}$ Assistant Professor, Department of Veterinary Public Health and Epidemiology, ${ }^{3}$ Associate Professor, Department of Animal Genetics and Breeding, ${ }^{4}$ Assistant Professor, Department of Livestock Products Technology, ARAWALI

VETERINARY COLLEGE (Affiliated with Rajasthan University of Veterinary and Animal Sciences, Bikaner), N.H. - 52 Jaipur Road, V.P.O. Bajor, Sikar - 332001, Rajasthan, India

\begin{abstract}
The present paper reports the microbiological examination and reporting of a clinical case of mastitis in female adult goat (doe) and its recommended therapeutic management with the selected broad spectrum antibiotics. The indiscriminate and injudicious administration of antibiotics and irrational treatment of mastitis with different antibiotics have invited serious complications like multiple drug resistance. Till date different types of antibiotics have been tried against the pathogens in mastitis with or without identification and drug sensitivity testing.
\end{abstract}

Keywords: Antibiotics, Antibiogram, Mastitis.

\section{INTRODUCTION}

Mastitis is usually caused by bacteria that invade the udder, multiply and produce toxins which are harmful to the mammary gland. It remains the most economically important disease of dairy industries around the world producing great economic loss to farmers. There are two forms of mastitis $v i z$, clinical and sub clinical forms. Mastitis the chronic inflammation of the mammary gland of lactating dairy animals and can have infectious and non-infectious etiology. It is characterized by physical, chemical and usually bacteriological changes in the milk and pathological changes in the glandular tissue of the udder and affects quality and quantity of milk. ${ }^{[1-4]}$

The present study was conducted to identify the etiology of clinical mastitis and the antibiotics/ antibacterial drugs which show sensitivity against the various pathogenic agents.

\section{MATERIALS AND MeTHODS}

Two (2 No.) of blood stained milk samples were collected by hand stripping method in two separate sterile sample collection tubes from the clinically fibrosed affected quarters of the udder of a doe exhibiting clinical symptoms of mastitis which was produced at the Teaching Veterinary Clinical Complex (T.V.C.C.) of the college. The collected milk samples were then forwarded to the Department of Veterinary Microbiology during October, 2016 for bacteriological investigation and reporting.

The milk samples were examined bacteriologically ${ }^{[5]}$ for the colony characteristics by nutrient agar plate culturing. Bacterial staining was done by Gram's Method ${ }^{[6]}$. The antibiotic sensitivity test was performed as per Kirby-Bauer antibiotic disc diffusion assay method on Mueller-Hinton agar plates with certain modifications ${ }^{[1]}$ using antibiotic discs provided by the supplier (Titan Biotech Ltd., Bhiwadi, Rajasthan, India). The concentration of antibiotic in each filter paper disc was as per the specification of the manufacturer required for laboratory purpose. Incubation of the petridishes layered with the agar containing antibiotic discs was done at $37^{\circ} \mathrm{C}$ for $24 \mathrm{~h}$ in a B.O.D. incubator installed at the department.

\section{RESULTS AND DISCUSSION}

The milk samples were subjected to spread plate culture on two separate Mueller Hinton agar media plates ${ }^{[6]}$ from the two samples. After incubation at $37^{\circ} \mathrm{C}$ for $24 \mathrm{~h}$ it showed the presence of smooth, 
raised, mucoid, circular colonies with regular edges in both the plates. Grams' method of staining revealed Gram positive cocci arranged in the form of chains when examined under the high power magnification of the compound microscope. The bacteria was bacteriologically determined to be grouped under Streptococcus spp. ${ }^{[4,6-9]}$

Antibiotic assay revealed the bacterial isolates to be highly sensitive to the antibiotics, Amikacin and Chloramphenicol with low degree of sensitivity to Streptomucin and Ceftriaxone respectively. The degree of sensitivity was determined on the basis of zone of inhibition formed by the isolated bacteria after exposure to the particular antibiotics by incubation.

The results obtained on cultural properties of the bacteria and its antibiotic disc diffusion assays revealed in the present study were in correlation with the findings of earlier investigators. ${ }^{[10-15]}$

\section{CONCLUSION}

The present study revealed the presence clinical of Streptococcus spp. of bacteria responsible for causing clinical mastitis in the fibrosed quarters of the udder of the doe. The bacterial strain was found to be sensitive to broad spectrum antibiotics which was reported and recommended to the T.V.C.C. for their administration in divided doses on alternate daily intervals in mixed preparations.

\section{ACKNOWLEDGEMENTS}

The authors are thankful to Hon'ble Dean and Management (Hony. Chairman and Secretary, Aastha Society, Sikar) of Arawali Veterinary College, Sikar for providing the necessary facilities to conduct the research work.

\section{REFERENCES}

[1] Patnaik, Subhasree, Prasad, Arun, Ganguly, Subha (2013). Mastitis, an Infection of Cattle Udder: A Review. J. Chem. Biol. Physical Sci., Section-B [Biological Sciences]. 3(4): 2676-8.

[2] Paul, I., Isore, D.P., Joardar, S.N., Mukhopadhayay, S.K., Ganguly, S., Pal, S. (2013). Bacteriological investigation and antibiogram on Methicillin-resistant Staphylococcus aureus (MRSA) causing subclinical mastitis in dairy cattle population of West Bengal. Indian J. Comp. Microbiol. Immunol. Infect. Dis., 34(2): 56-9.

[3] Ganguly, Subha (2014). A comprehensive and illustrious review on clinical and diagnostic aspects of Mastitis infection in high yielding lactating cows. World J. Pharma. Res., 3(9): 35260.

[4] Wakchaure, Rajesh, Ganguly, Subha, Para, Parveez Ahmad, Praveen, Praveen Kumar, Qadri, Kausar (2015). Mastitis, an economically important disease affecting lactating ruminants: A Review. Chap. 15, pp. 199-212. In: New Dimensions in Microbiology [Eds. Dr. M.M. Abid Ali Khan (India), Dr. John K. Grandy (USA), Dr. Egamberdieva Dilfuza (Germany), Murataza Abid (India), Dr. Raaz K. Maheshwari (India), Dr. T.S. Naqvi (India)], Lenin Media, Delhi, India. ISBN 978-93-85160-84-4.

[5] Buxton, A., Fraser, G. (1977). Animal Microbiology. Vol. 1. Blackwell Scientific Publications.

[6] Sinha, S.N. (2006). Focus on College Practical Microbiology. Part-I. Rita Book Agency, Kolkata, India.

[7] Ananthanarayan, R., Paniker, C.K. Jayaram. (2009). Textbook of Microbiology. $8^{\text {th }}$ ed. Universities Press (India) Pvt. Ltd. Hyderabad, India. ISBN 9788173716744.

[8] Cruickshank, R., Duguid, J.P., Marmion, B.P., Swain, R.H.A. (1975). Medical Microbiology. 12th ed. Vol. II, Churchill Livingstone, London.

[9] Finegold, S.M., Martin, M.J. (1982). Diagnostic Microbiology. 6th ed. The C.V. Morsby Co., London.

[10] Ganguly, Subha, Padhy, Arpita, Sahoo, Saraswat, Garg, Shyam Lal, Praveen, Praveen Kumar, Wakchaure, Rajesh, Para, Parveez Ahmad, Sharma, Subhash, Kumar, Avinash, Pandey, Arvind Kumar, Mahajan, Tanvi, Qadri, Kausar (2015). Bacteriological examination and antibiogram of milk sample of clinically infected dairy cow suffering from mastitis. Int. J. Medi. Microbiol. Trop. Dis., 1(1): 6-7.

[11] Ganguly, Subha, Padhy, Arpita, Sahoo, Saraswat, Garg, Shyam Lal, Wakchaure, Rajesh, Praveen, Praveen Kumar, Para, Parveez Ahmad, Mahajan, Tanvi, Qadri, Kausar, Sharma, Ruchi 
(2016). Antibiogram of milk sample of a farm maintained dairy cow suffering from mastitis followed by its clinical recovery. Int. J. Sci. Environ. Technol., 5(1): 148-151.

[12] Ganguly, Subha, Qadri, Kausar, Praveen, Praveen Kumar (2016) Bacteriological analysis of mastitic milk sample. Int. J. Multidiscipl. Res. Modern Edu. II(I): 468-470.

[13] Kumar, Mayur, Prasad, Arun, Tiwary, B.K., Ganguly, Subha (2010). Study on incidence of mastitis in cattle population of Ranchi (Jharkhand) under different dairy farm conditions. Livest. Line, 4(6): pp. 8.

[14] Patnaik, Subhasree, Prasad, Arun, Ganguly, Subha (2014). Biochemical characterization and antibiogram of Staphylococcal microorganisms associated with subclinical mastitis in lactating crossbred cows. Anim. Sci. Rep., 8(4): 123-9.

[15] Ganguly, Subha and Wakchaure, Rajesh (2016) Bacteriological analysis of cow milk sample suspected of being affected with sub-clinical mastitis. Int. J. Engg. Innov. Technol. 6(3): 38-39. 